\title{
Evaluation of Toxic Activities of Polycyclic Aromatic Hydrocarbon Derivatives Using In Vitro Bioassays
}

\author{
Kanae Bekki, ${ }^{*},{ }^{b}$ Hidetaka Takigami, ${ }^{b}$ Go Suzuki, ${ }^{b, c}$ Ning Tang, ${ }^{d}$ \\ and Kazuichi Hayakawa ${ }^{a, d}$
}

${ }^{a}$ Graduate School of Natural Science and Technology, Kanazawa University, Kakuma-machi, Kanazawa 920-1192, Japan, ${ }^{b}$ Research Center for Material Cycles and Waste Management, National Institute for Environmental Studies, 16-2 Onogawa, Tsukuba, Ibaraki 305-8506, Japan, ${ }^{c}$ Center for Marine Environmental Studies, Ehime University, 2-5 Bunkyo-cho, Matsuyama 790-8577, Japan and ${ }^{d}$ Institute of Medical, Pharmaceutical and Health Sciences, Kanazawa University, Kakuma-machi, Kanazawa 920-1192, Japan

(Received May 2, 2009; Accepted June 9, 2009; Published online June 10, 2009)

\begin{abstract}
Several polycyclic aromatic hydrocarbons and nitrated polycyclic aromatic hydrocarbons (PAHs/NPAHs) such as benzo[ $a]$ pyrene and 1-nitropyrene are mutagens and/or carcinogens. These compounds secondarily generate PAH hydroxides, ketones, and quinones through atmospheric and metabolic reactions. The health effects of these compounds is now an important social concern. For example, lung cancer, bronchitis, whistling and so on. In this work, we evaluated toxicities of 25 PAH derivatives (hydroxides, ketones and quinones) in terms of aryl hydrocarbon receptor (AhR) binding and thyroid hormone-related endpoints using three in vitro bioassays: dioxinresponsive chemical-activated luciferase gene expression (DR-CALUX), thyroid receptor $\beta$ chemical-activated luciferase gene expression (TR $\beta$-CALUX), and competitive human transthyretin-binding (TTR-binding) assays. Eleven of the 25 PAH derivatives had AhR agonist activity, six had AhR antagonist activity and seven had TRpotentiation activity in the TR-CALUX. Furthermore, PAH quinones and hydroxides had strong TTR-binding activity. 3,4-Dihydrobenz[ $a$ ] anthracen- $1(2 \mathrm{H})$-one had the strongest agonist activity $\left(\mathrm{EC}_{20}: 0.4 \mu \mathrm{M}\right)$ as determined by DR-CALUX. PAH ketones showed stronger activity than the control and significant difference by statistical analysis. Benzo[c]phenanthrene-[1,4]-quinone was the most TTR-active compound $\left(\mathrm{IC}_{50}: 2.5 \mu \mathrm{M}\right)$. Both PAH ketones and quinones, which have functional groups with low polarity, had significant activities in all tested assays. These in vitro results suggest that PAH derivatives might have various toxic activities in animals. For estimating the health effects and accessing the environmental risks of PAHs, further studies on the toxicity mechanisms are necessary.
\end{abstract}

Key words — polycyclic aromatic hydrocarbon derivatives, bioassay, aryl hydrocarbon receptor, thyroid receptor, transthyretin

\section{INTRDUCTION}

Polycyclic aromatic hydrocarbons (PAHs), which originate from combustion of biomass or fossil fuels such as petroleum and coal, are pollutants that are distributed ubiquitously throughout the environment. Many of them induce mutagenic and/or carcinogenic effects. ${ }^{1)}$ Furthermore, PAHs are known to possess aryl hydrocarbon receptor (AhR) binding activity, which has been used as a criterion for dioxin-like activity. ${ }^{2)}$ In fact, AhR-derived gene expressions by novel AhR agonists such as

*To whom correspondence should be addressed: Graduate School of Natural Science and Technology, Kanazawa University, Kakuma-machi, Kanazawa 920-1192, Japan. Tel.: +81-76-234-4458; Fax: +81-76-234-4456; E-mail: k.bekki@ stu.kanazawa-u.ac.jp polychlorinated dibenzo- $p$-dioxins/dibenzofurans (PCDD/DFs) and polychlorinated biphenyls (PCBs) are associated with various diseases: weight loss, thymus shrinking, hepatic toxicity, teratogenesis, reproduction disorders, endocrine disorders and cancer. ${ }^{3,4)}$ PAHs are more easily metabolized than halogenated compounds, but they also elicit several toxic and biochemical responses such as derivation of drug-metabolizing enzymes (cytochrome P450 1A1, 1A2, 1B1, etc.). Additionally, PAHs are transformed into derivatives by chemical reactions in the air and metabolic reactions in the body. For example, oxygenated PAHs such as ketones and quinones are formed by either combustion or gas phase photooxidation (in airborne particles). ${ }^{5}$ ) The concentration of 9,10-phenanthrenquinone $(9,10-P Q)$ was measured in the range from 0.138 
to $0.690 \mathrm{ng} \mathrm{m}^{-3}$ at Nagasaki, Japan. ${ }^{6)}$ The levels of 9,10-PQ were correlated with those of phenanthrene, a parent compound of 9,10-PQ, up to a few $\mathrm{ng} \mathrm{m}^{-3}$. Furthermore, PAH quinones are generated by metabolizing PAHs in the presence of P450, epoxide hydrolase and some other metabolic enzymes. ${ }^{7)}$

Some recent reports described the toxicity of PAH derivatives. Among toxic PAH derivatives, PAH hydroxides are androgen antagonists $^{8)}$ and PAH quinones induce the generation of reactive oxygen species (ROS). ${ }^{9}$ ) Furthermore, polyhalogenated aromatic hydrocarbons (PHAHs), their hydroxylated derivatives ${ }^{10)}$ and 2,3,7,8-tetrachlorodibenzo- $p$-dioxin $(2,3,7,8$ TCDD) bind to thyroid hormone transporting protein, transthyretin (TTR) ${ }^{11)}$ and reduce the T4 level in rat blood plasma. ${ }^{12)}$ But the effects of PAH and $\mathrm{PAH}$ derivatives on the mechanisms is unknown, in spite of their high concentrations in the atmosphere suggesting large amount of human exposure.

The goal of this study was to determine the toxic potentials of $25 \mathrm{PAH}$ derivatives including hydroxides, ketones, and quinones in terms of $\mathrm{AhR}$ binding and thyroid hormone-related endpoints using three in vitro bioassays: dioxin-responsive chemical-activated luciferase gene expression (DRCALUX), thyroid receptor $\beta$ chemical-activated luciferase gene expression (TR $\beta$-CALUX) and competitive human TTR-binding assays.

\section{MATERIALS AND METHODS}

Materials — We selected following twenty-five PAH derivatives (eight ketones, nine quinines and eight hydroxides) having two to four rings in terms of their existing in the air, ${ }^{13)}$ endocrine disruption and strong ROS producing activity. Anthrone, benzanthrone, 9-fluorenone, 2-hydroxy-9-fluorenone, 2,2'-biphenol, 1,2-naphthoquinone (1,2-NQ), 1,2-dihydroxynaphthalene, and 4,4'-biphenol were purchased from Tokyo Chemical Industry Co. Ltd. (Tokyo, Japan). 3,4-Dihydrobenz[a]anthracen-1 $(2 \mathrm{H})$-one, and 1,4-naphthoquinone (1,4-NQ) were purchased from Sigma-Aldrich Corp. (Tokyo, Japan). Trans-9,10-dihydrodiolphenanthrene, 11Hbenzo[ $a$ ]fluoren-11-one, 11H-benzo[ $b]$ fluoren-11one, 1-hydroxy-9-fluorenone, 5,6,8,9-tetrahydrobenz[ $a$ ]anthracen-11(OH)-one, 9,10-PQ, 1,4anthra-quinone (1,4-AQ), 5,6-chrysenequinone (5,6-CQ), 1,4-chrysenequinone (1,4-CQ), benzo[c]- phenanthrene- $[1,4]$-quinone $\quad(\mathrm{B}[c] \mathrm{P}-1,4-\mathrm{Q}), \quad 1-$ hydroxyphenanthrene (1-OHPhe), 2-hydroxyphenanthrene (2-OHPhe), 4-hydroxyphenanthrene (4-OHPhe), and 9-hydroxyphenanthrene (9OHPhe) were purchased from Chiron AS (Trondheim, Norway). 1,2-Benzanthraquinone (1,2-BAQ) was purchased from Wako Pure Chemical Industries Ltd. (Tokyo, Japan). The respective structures of the PAH derivatives listed above are presented in Fig. 1. Each concentration of the test compound was prepared in dimethylsulfoxide (DMSO).

DR-CALUX Assay — AhR binding activity was measured using the DR-CALUX assay using the rat hepatoma H4IIE cell line with an AhR-regulated luciferase gene construct (H4IIE-luc). The H4IIE-luc cell line was obtained from BioDetection Systems B.V. (Amsterdam, The Netherlands). The cells were cultured in alpha-minimal essential medium $(\alpha-$ MEM) (Invitrogen Corp., New York, NY, U.S.A.) supplemented with $10 \%$ fetal bovine serum (FBS) at $37^{\circ} \mathrm{C}$ under $5 \% \mathrm{CO}_{2}$. The cells were seeded into a 96-well microplate and the cells with 90$95 \%$ confluence were used for exposure. All test compounds were evaluated in terms of agonist, antagonist, and potentiating activities. For evaluation of agonistic activity, the cells were exposed to $2,3,7,8$-TCDD standard series $(0,0.1,0.3,1,3$, $10,30,100,300 \mathrm{pM}$ in well) and experimental samples in the culture medium containing $0.4 \%$ DMSO in the same microplate. After $24 \mathrm{hr}$ of exposure, the medium was removed. Then the microplate was filled with $50 \mu \mathrm{l}$ of Meliorastar-LT (Toyo B-net Co. Ltd., Tokyo, Japan). After 10 min of enzyme reaction in a dark place at room temperature, luciferase activity was measured using a luminometer (AB-2100; ATTO Bioscience, Tokyo, Japan) for $10 \mathrm{~s}$ per well. For data analysis, after correcting for background activity (DMSO control), luciferase activities by 2,3,7,8-TCDD were fitted using software for a user-defined curve fit (Slide Write Plus ver. 6.00; Advanced Graphics Software, St. California, Encinitas, U.S.A.). The curve was $y=$ $a_{0} /\left[1+\left(x / a_{1}\right)^{a_{2}}\right]$ with the following parameters: $y=$ measured luciferase activity; $x=$ concentration; $a_{0}$ $=$ maximum luciferase activity; $a_{1}=\mathrm{EC}_{50}$; and $a_{2}=$ curve slope. For evaluation of agonistic activity, full dose-response curves were not obtainable for the tested compounds. Consequently, luciferase activities of the tested compounds corresponding to $\mathrm{EC}_{5}$, $\mathrm{EC}_{20}$, and $\mathrm{EC}_{50}(5,20$, and $50 \%$ Effective Concentrations) of 2,3,7,8-TCDD were used to define $\mathrm{EC}_{5}$, $\mathrm{EC}_{20}$, and $\mathrm{EC}_{50}$ concentrations of each compound, 


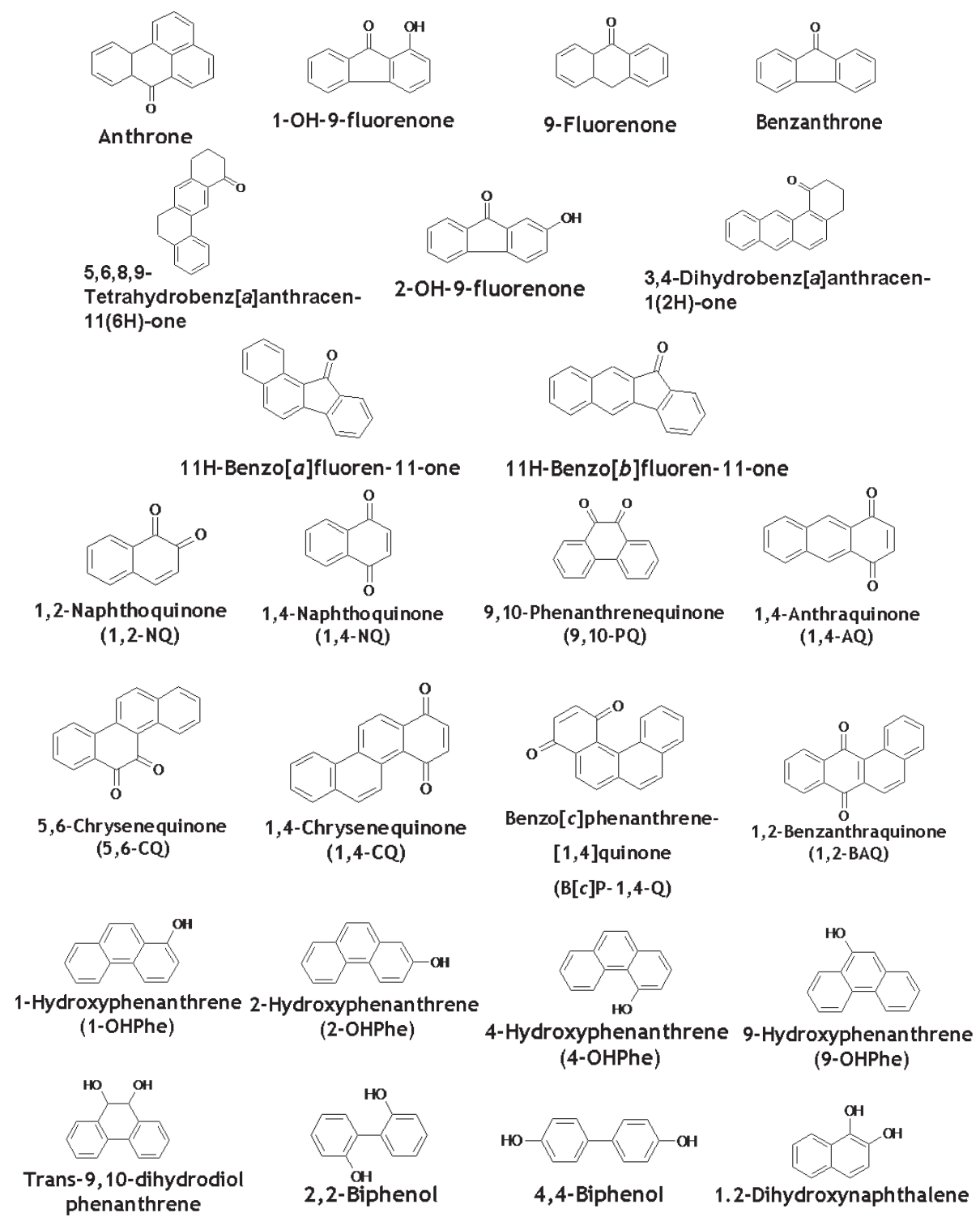

Fig. 1. Structures of PAH Derivatives Tested in This Study

as described in a previous report. ${ }^{14)}$

On the other hand, for measurement of antagonist and potentiation activities, the cells were exposed to 2,3,7,8-TCDD standard $\left(\mathrm{EC}_{50}: 7.5 \mathrm{pM}\right.$ in well) and experimental samples together. The luciferase activity was measured using a luminometer after $24 \mathrm{hr}$ of exposure. Antagonistic and potentiation effects were defined by the capacity of a tested compound to inhibit or enhance the luciferase activity induced by $2,3,7,8$-TCDD. Here, potentiation means an increase of agonistic activity through co-exposure of 2,3,7,8-TCDD and a non-agonistic compound.

TR-CALUX Assay — Human TR $\beta$-binding activity was measured using the TR-CALUX assay with the human osteosarcoma U2OS cell line and a human thyroid receptor $\beta$ regulated luciferase gene construct (U2OS-luc) The U2OS-luc cell line was obtained from BioDetection Systems B.V. (Amsterdam, The Netherlands). The cells were cultured in Dulbecco's modified eagle medium (DMEM) supplemented with 10\% FBS treated by activated carbon, sterilized MEM non-essential amino acids, $(100 \times)$ Solution (NEAA) (Invitrogen Corp., New York, NY, U.S.A.), $\mathrm{NaHCO}_{3}$ (Kanto Chemical Co. Inc., Tokyo, Japan), penicillin/streptomycin (Sigma-Aldrich Corp.), and G-418 disulfate (Sigma-Aldrich Corp.) at $37^{\circ} \mathrm{C}$ under $7.5 \% \quad \mathrm{CO}_{2}$. The cells were seeded into 96-well microplates and the cells with 90-95\% confluence were used for exposure. The cells were exposed to $200 \mu 1 /$ well T3 standard series $(0,0.04$, 
$0.12,0.4,1.2,4,12,40,120$, and $400 \mathrm{nM}$ in well) or experimental samples in the culture medium containing $0.1 \%$ DMSO. After $48 \mathrm{hr}$ of exposure, the medium was removed and the microplate was filled with $50 \mu \mathrm{l}$ of Meliorastar-LT (Toyo B-net Co. Ltd.). After eight-minute enzyme reaction on the plate shaker, the luciferase activity was measured in a multilabel counter (PerkinElmer Inc., Tokyo, Japan). For measurement of the antagonist and potentiation activities, the cells were exposed to $\mathrm{T} 3$ standard $\left(\mathrm{EC}_{50}: 2 \mathrm{nM}\right.$ in well) and experimental reagents together for $48 \mathrm{hr}$, and luciferase activity was measured using the multilabel counter. Data analyses for evaluation of agonistic/antagonistic/potentiation activities were conducted similarly to those for DR-CALUX.

TTR-Binding Assay — Human TTR (SigmaAldrich Corp.; $30 \mathrm{~nm}$ ) was incubated overnight at $4^{\circ} \mathrm{C}$ in a final volume of $200 \mu l 0.1 \mathrm{M}$ Tris- $\mathrm{HCl}$ buffer ( $\mathrm{pH} 8.0 ; 0.1 \mathrm{M} \mathrm{NaCl}, 0.1 \mathrm{mM}$ ethylene diamine tetra-acetic acid (EDTA)) with a mixture of ${ }^{125}$ I-labeled (PerkinElmer Inc.; $3.7 \mathrm{MBq}$ ) and ${ }^{125} \mathrm{I}$ unlabeled T4 (Sigma-Aldrich Corp.; $110 \mathrm{nM}$ ), with test compounds (maximum concentration $25 \mu \mathrm{M}$ ) or cold T4 (reference material) as competitors. All treatments and carrier controls contained 2.5\% DMSO. When the binding equilibrium was reached, TTR-bound and free ${ }^{125} \mathrm{I}-\mathrm{T} 4$ were separated on 1-ml Biogel P-6 pg columns and spin-force eluted with $200 \mu \mathrm{l}$ Tris- $\mathrm{HCl}$ buffer ( $1 \mathrm{~min}, 1000 \mathrm{rpm}, 4^{\circ} \mathrm{C}$ ). The TTR-bound ${ }^{125} \mathrm{I}-\mathrm{T} 4-$ containing eluate was counted for radioactivity using a gamma counter (WIZARD 1480; PerkinElmer Inc.). Competition-bindings of T4 standards and standard substances were expressed as relative ${ }^{125} \mathrm{I}-\mathrm{T} 4$ TTR-binding (\% of DMSO control) against competitors. A calibration competition-binding curve for T4 standards $(0,4$, $8,16,32,64,128,256,512,1024 \mathrm{nM}$ in tube) were also fitted using a user-defined curve fit (Slide Write Plus ver. 6.00; Advanced Graphics Software) of $y=a_{0} /\left[1+\left(x / a_{1}\right)^{a_{2}}\right]$, for which $y=$ measured ${ }^{125} \mathrm{I}-$ T4 TTR-binding, $x=$ concentration, $a_{0}={ }^{125} \mathrm{I}-\mathrm{T} 4$ TTR-binding of DMSO control, $a_{1}=\mathrm{IC}_{50}$, and $a_{2}=$ curve slope. All measurements were conducted in duplicate. All experiments were performed twice. Cytotoxicity - Cytotoxicity was measured for the DR-CALUX and TR-CALUX cells to ensure that reduction activity resulted from antagonistic responses and not by cytotoxicity. The reference agonist $\left(100 \times \mathrm{EC}_{50}\right)$ was exposed to each assay cells with a sample which showed antagonistic activity. A similarly referenced agonist $\left(\mathrm{EC}_{50}\right)$ and the same sample were also exposed to each assay cell. Antagonistic responses in cell-based bioassays were competed out in most cases by excess of the reference agonist $\left(100 \times \mathrm{EC}_{50}\right)$, so inhibition might be attributable to true antagonism and not to cytotoxicity.

Statistics — The statistical significance of the activity difference between compound and control groups was determined using a Student's $t$-test $(p<0.05)$. The agonist, antagonist or potentiation activity was evaluated when the significant difference was observed at least one of the highest exposure concentration.

\section{RESULTS}

\section{DR-CALUX Assay}

Eleven PAH derivatives showed marked AhR agonist activity (Fig. 2). Five PAH derivatives showed AhR antagonist activity (Fig. 3).

Table 1 shows results of $\mathrm{EC}_{5}$ and $\mathrm{EC}_{20}$ of the $\mathrm{AhR}$ agonist compounds. Although $\mathrm{EC}_{5}$ and $\mathrm{EC}_{20}$ do not show the same ranking order, the tendency is the same. The most potent compound was 3,4-dihydrobenz $[a]$ anthracen-1 $(2 \mathrm{H})$ one $\left(\mathrm{EC}_{20}: 0.4 \mu \mathrm{M}\right)$. Other active compounds in order of AhR agonist activity were the following: 1,4chrysenequinone $>1$,2-benzanthraquinone $>$ benzanthrone $\approx 11 \mathrm{H}$-benzo[a]fluoren-11-one $>11 \mathrm{H}$ benzo[ $b]$ fluorene-11-one. In this study, PAH derivatives having 2-4 aromatic rings were tested. Especially $\mathrm{PAH}$ quinones with four rings and $\mathrm{PAH}$ ketones with three or four rings had AhR agonist activity [Fig. 2(a), (c)], which raises the possibility of a structure-activity relationship. This relationship was observed in the estrogenic and antiestrogenic activities of hydroxylated PAHs with two to six rings through ER binding. ${ }^{15)}$ The author is now studying on the AhR agonistic and antagonistic activity of PAH quinones and ketones with five rings or more to classify the structure activity relationship.

\section{TR-CALUX Assay}

TR agonistic/antagonistic effects were not observed for the tested compounds in the concentration range of this study. However, interestingly, 7 PAH derivatives showed potentiating activity (Fig. 4). These potentiating activities appeared at concentrations over $1 \mu \mathrm{M}$ (in well). $11 \mathrm{H}$ Benzo[ $a]$ fluoren-11-one elicited the highest poten- 

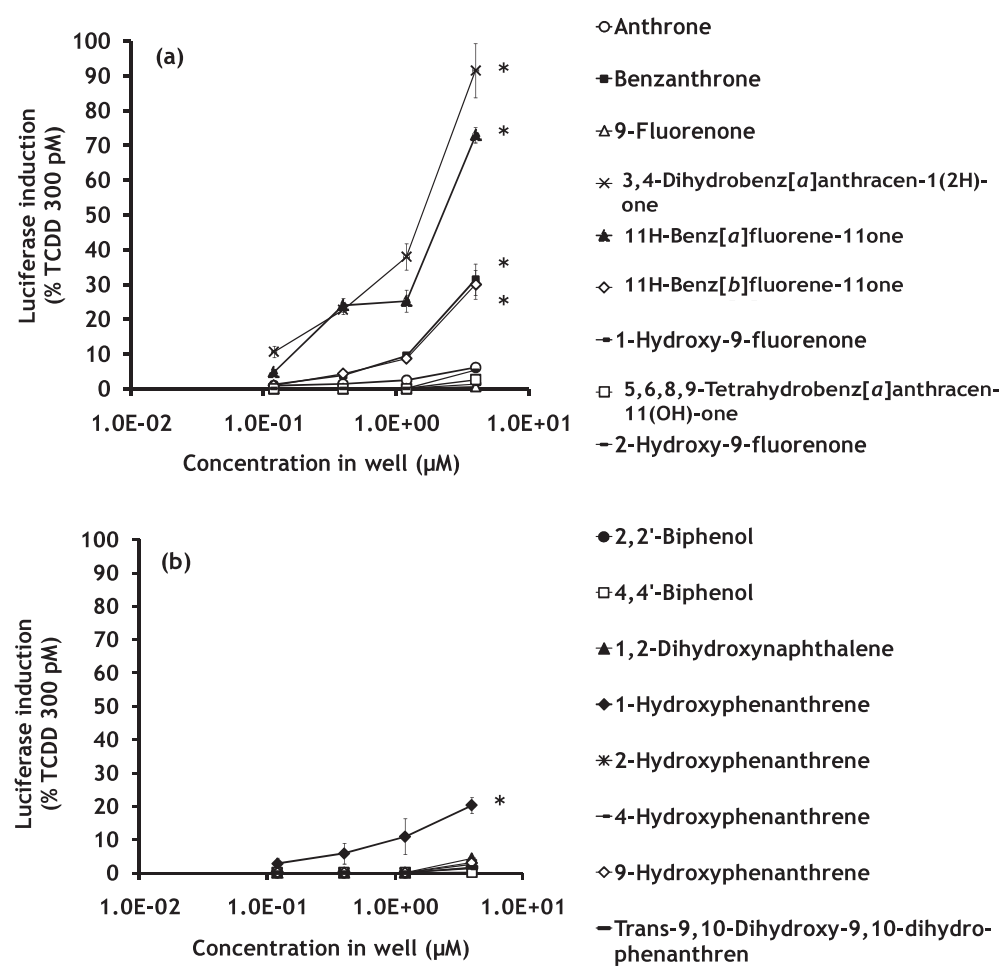

phenanthren

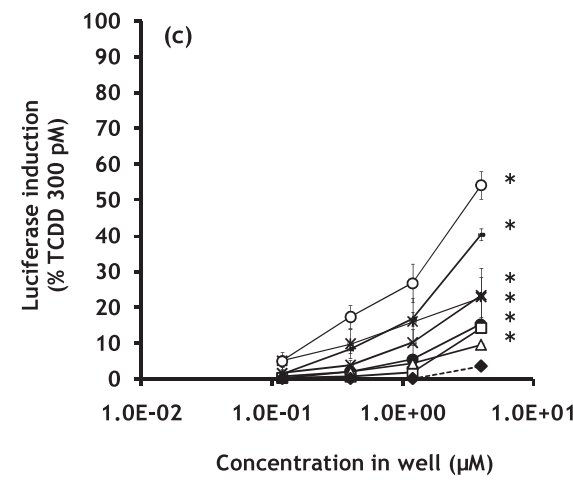

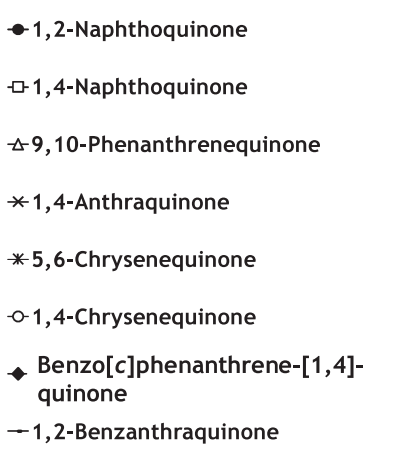

Fig. 2. AhR Agonist Activity of the Tested PAH Derivatives

(a) PAH ketones, (b) PAH hydroxides, (c) PAH quinones. Agonist activities of the PAH derivatives were expressed relative to 2,3,7,8-TCDD activity level induced by $300 \mathrm{pM}(100 \%)$. Symbols and vertical bars respectively represent the mean and \pm S.D. $(n=5)$. Asterisk $(*)$ shows significant difference.

tiating activity. The relative to the activity of $\mathrm{T} 3$ at $25 \mu \mathrm{M}$ is over $200 \%$ [Fig. 4(a)].

\section{TTR-Binding Assay}

Table 2 shows TTR-binding assay results: ${ }^{125} \mathrm{I}-$ T4 binding (\% of control) ratio values for the tested PAH derivatives at a concentration of $25 \mu \mathrm{M}$. Seventeen compounds had TTR-binding activity. Among those compounds, $\mathrm{B}[c] \mathrm{P}-1,4-\mathrm{Q}$ had the highest binding ratio of approximately $90 \%$. In contrast, 2-OHPhe, 2,2'-biphenol and PAH ketones had no TTR-binding activity. The rank order of potent compounds was as follows: $\mathrm{B}[c] \mathrm{P}-[1,4]-\mathrm{Q}>1,4-$ $\mathrm{CQ}>1,4-\mathrm{AQ}>1,4-\mathrm{NQ}>1$-OH-9-fluorenone $>$ 4,4'-biphenol $>1$-OHPhe $\approx 4$-OHPhe $>$ 9-OHPhe. This shows that PAH quinones had comparatively higher activity than the others. The difference between the results of AhR agonistic activity obtained by DR-CALUX and those of TTR-binding activity suggests that functional groups on the aromatic ring have an effect to the binding to AhR.

\section{DISCUSSION}

The PAH derivatives examined in this study were polar compounds (i.e., ketones and quinones) compared with their parental PAHs and possess 
Table 1. DR-CALUX REP Values for the Tested PAH Derivatives

\begin{tabular}{lcccl}
\hline \hline PAH derivative & $\mathrm{EC}_{5}(\mu \mathrm{M}) \pm \mathrm{S} . \mathrm{D}$. & $\mathrm{EC}_{20}(\mu \mathrm{M}) \pm \mathrm{S} . \mathrm{D}$. & $\mathrm{REP} \mathrm{EC}_{5}$ & REP EC $_{20}$ \\
\hline Benzanthrone & $0.6 \pm 0.04$ & $2.4 \pm 0.3$ & $8.3 \mathrm{E}-07$ & $1.1 \mathrm{E}-06$ \\
3,4-Dihydrobenz $[a]$ anthracen-1 $(2 \mathrm{H})$-one & $0.1 \pm 0.01$ & $0.4 \pm 0.03$ & $5.0 \mathrm{E}-06$ & $1.82 \mathrm{E}-07$ \\
11H-Benzo- $[a]$ fluoren-11one & $0.6 \pm 0.05$ & $2.4 \pm 0.7$ & $8.3 \mathrm{E}-07$ & $1.1 \mathrm{E}-06$ \\
11H-Benzo-[$[b]$ fluoren-11one & $0.6 \pm 0.09$ & $2.7 \pm 0.3$ & $8.3 \mathrm{E}-07$ & $1.2 \mathrm{E}-06$ \\
1,2-Naphthoquinone & $1.1 \pm 0.06$ & $5.4 \pm 0.3$ & $4.5 \mathrm{E}-07$ & $2.5 \mathrm{E}-06$ \\
1,4-Naphthoquinone & $2.1 \pm 0.2$ & 4.9 & $2.4 \mathrm{E}-07$ & $2.2 \mathrm{E}-06$ \\
1,4-Anthraquinone & $0.6 \pm 0.0005$ & $4.1 \pm 0.7$ & $8.3 \mathrm{E}-07$ & $1.9 \mathrm{E}-06$ \\
5,6-Chrysenequinone & $0.3 \pm 0.03$ & $2.4 \pm 0.3$ & $1.7 \mathrm{E}-06$ & $1.1 \mathrm{E}-06$ \\
1,4-Chrysenequinone & $0.1 \pm 0.003$ & $0.6 \pm 0.1$ & $5.0 \mathrm{E}-06$ & $2.7 \mathrm{E}-07$ \\
1,2-Benzanthraquinone & $0.3 \pm 0.02$ & $1.6 \pm 0.1$ & $1.7 \mathrm{E}-06$ & $7.3 \mathrm{E}-07$ \\
1-Hydroxyphenanthrene & $0.6 \pm 0.05$ & $4.5 \pm 0.4$ & $8.3 \mathrm{E}-07$ & $2.0 \mathrm{E}-06$ \\
TCDD & $(5.0 \pm 0.3) \mathrm{E}-07$ & $(2.2 \pm 0.2) \mathrm{E}-06$ & $1.0 \mathrm{E}+00$ & $1.0 \mathrm{E}+00$ \\
\hline
\end{tabular}

All measurements were conducted in triplicate. All experiments were performed five times. Relative potency (REP) values based on $\mathrm{EC}_{5}$ and $\mathrm{EC}_{20}$ were calculated, respectively, by dividing $\mathrm{EC}_{5}$ and $\mathrm{EC}_{20}$ for TCDD by $\mathrm{EC}_{5}$ and $\mathrm{EC}_{20}$ for the test compound.

Table 2. ${ }^{125}$ I-T4 Binding Values for the Tested PAH Derivatives

\begin{tabular}{|c|c|c|}
\hline \multirow[t]{2}{*}{ PAH derivative } & \multicolumn{2}{|c|}{${ }^{125} \mathrm{I}-\mathrm{T} 4$ binding (\% of control) } \\
\hline & average & S.D. \\
\hline Anthrone & - & - \\
\hline Benzanthrone & - & - \\
\hline 9-Fluorenone & - & - \\
\hline 3,4-Dihydrobenz $[a]$ anthracen-1(2 H)-one & - & - \\
\hline Trans-9,10-Dihidroxy-9,10-dihydro-phenanthrene & - & - \\
\hline 11H-Benzo $[a]$ fluoren-11-one & - & - \\
\hline 11H-Benzo[b]fluoren-11-one & - & - \\
\hline 1-Hydroxy-9-fluorenone & 30 & 1 \\
\hline 5,6,8,9-Tetrahydrobenz $[a]$ anthracen-11(OH)-one & - & - \\
\hline 2-Hydroxy-9-fluorenone & 86 & 1 \\
\hline 2,2'-Biphenol & - & 8 \\
\hline 4,4'-Biphenol & 40 & 7 \\
\hline 1,2-Dihydroxynaphthalene & 58 & 1 \\
\hline 1,2-Naphthoquinone & 78 & 4 \\
\hline 1,4-Naphthoquinone & 24 & 1 \\
\hline 9,10-Phenanthrenequinone & 83 & 6 \\
\hline 1,4-Anthraquinone & 16 & 3 \\
\hline 5,6-Chrysenequinone & 73 & 10 \\
\hline 1,4-Chrysenequinone & 15 & - \\
\hline Benzo $[c]$ phenanthrene- $[1,4]$-quinone & 9 & 2 \\
\hline 1,2-Benzanthraquinone & 75 & 8 \\
\hline 1-Hydroxyphenanthrene & 47 & 13 \\
\hline 2-Hydroxyphenanthrene & - & 0 \\
\hline 4-Hydroxyphenanthrene & 47 & 6 \\
\hline 9-Hydroxyphenanthrene & 50 & - \\
\hline
\end{tabular}

A hyphen denotes a lack of TTR-binding activity. All measurements were conducted in duplicate, and all experiments were performed once or twice. The concentration of test compound was $25 \mu \mathrm{M}$.

weaker binding activity for AhR than PAHs do. Because the binding activities of PAH ketones and quinones were stronger than those of hydroxylated PAHs. ${ }^{16)}$ It has been reported that oxygenated PAHs which are polar compounds contribute more greatly than PAHs to the AhR activity of environmental air samples. ${ }^{17}$,18) PAH ketones and quinones originating from gasoline and diesel engine exhausts are present at comparatively high concentrations (e.g., $11 \mathrm{H}$-benzo[a]fluoren-11-one: $1.026 \pm 0.037 \mathrm{ng} / \mathrm{m}^{3}$, 


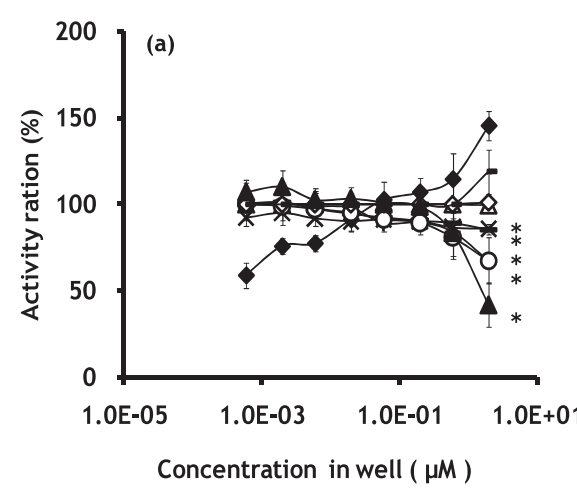

-Anthrone

+Benzanthrone

$\Delta$ 9-Fluorenone

* 3,4-Dihydrobenz[ $a$ ]anthracen-1(2H)-one

- 11H-Benz[a]fluorene-11one

-o 11H-Benz[b]fluorene-11one

$\diamond 1$-Hydroxy-9-fluorenone

$5,6,8,9$-Tetrahydrobenz [ $a$ ]anthracen$11(\mathrm{OH})$-one

- -2-Hydroxy-9-fluorenone

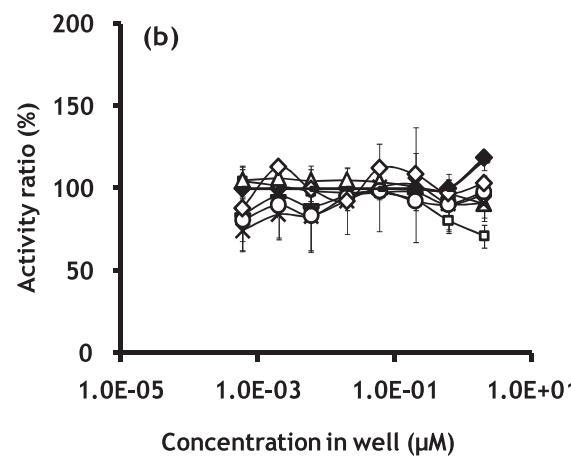

-2,2'-Biphenol

- 4,4'-Biphenol

$\Delta$ 1,2-Dihydroxynaphthalene

*1-Hydroxyphenanthrene

-2-Hydroxyphenanthrene

o-4-Hydroxyphenanthrene

$\diamond 9$-Hydroxyphenanthrene

- Trans-9,10-Dihydroxy-9,10dihydro-phenanthren

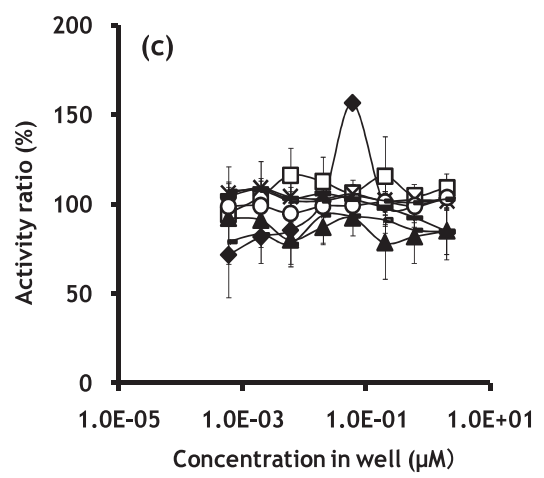

$\downarrow 1,2-$ Naphthoquinone

$\square$ 1,4-Naphthoquinone

$₫ 9,10$-Phenanthrenequinone

$* 1,4$-Anthraquinone

- 5,6-Chrysenequinone

0-1,4-Chrysenequinone

$\rightarrow$ Benzo[c]phenanthrene-[1,4]-

quinone

-1,2-Benzanthraquinone

Fig. 3. AhR Antagonist Activity of the Tested PAH Derivatives

(a) PAH ketones, (b) PAH hydroxides, (c) PAH quinones. Antagonist activities of the PAH derivatives were expressed by the activity ratio. Activity ratio $=[$ Luciferase activity of the PAH derivative $+2,3,7,8-\mathrm{TCDD}(7.5 \mathrm{pM}) /$ Luciferase activity of 2,3,7,8-TCDD $(7.5 \mathrm{pM})] \times 100$. Symbols and vertical bars respectively represent the mean and \pm S.D. $(n=5)$. Asterisk $(*)$ shows significant difference.

11H-benzo[b]fluoren-11-one: $0.852 \pm 0.036 \mathrm{ng} / \mathrm{m}^{3}$ ) in urban air ${ }^{5)}$ comparing with other detected compounds, and 9,10-PQ also exist at high concentration in ambient air. ${ }^{6)}$ The high concentration of PAH ketones and quinones in the atmosphere suggest that large amount of human exposure to these compounds through respiration.

Although the AhR binding activity of hydroxylated PAHs were lower than those of PAH quinones and ketones, hydroxylated PAHs are in cigarette smoke $^{19)}$ and act as endocrine disruptors (i.e., having estrogen-like activity). Several PAH hydroxides were shown to have estrogenic/antiestrogenic activity in a reporter gene assay. ${ }^{20,21)}$ Additionally, air samples reportedly possess toxicity such as mutagenicity, carcinogenicity and reactive oxygen species. ${ }^{22,23)}$ As a possible contributor to these activities, PAHs and/or PAH derivatives such as ketones and quinines are considered. The phenomenon of 1,4-Chrisenequinone's bell-shaped activity was similar to that of endocrine-disrupter chemicals (Fig. 3). This mechanism is unknown, but further studies are needed.

PAH derivatives did not show any significant $\operatorname{TR} \beta$ agonist or antagonist activity. Therefore, it is presumed that PAH derivatives do not bind di- 

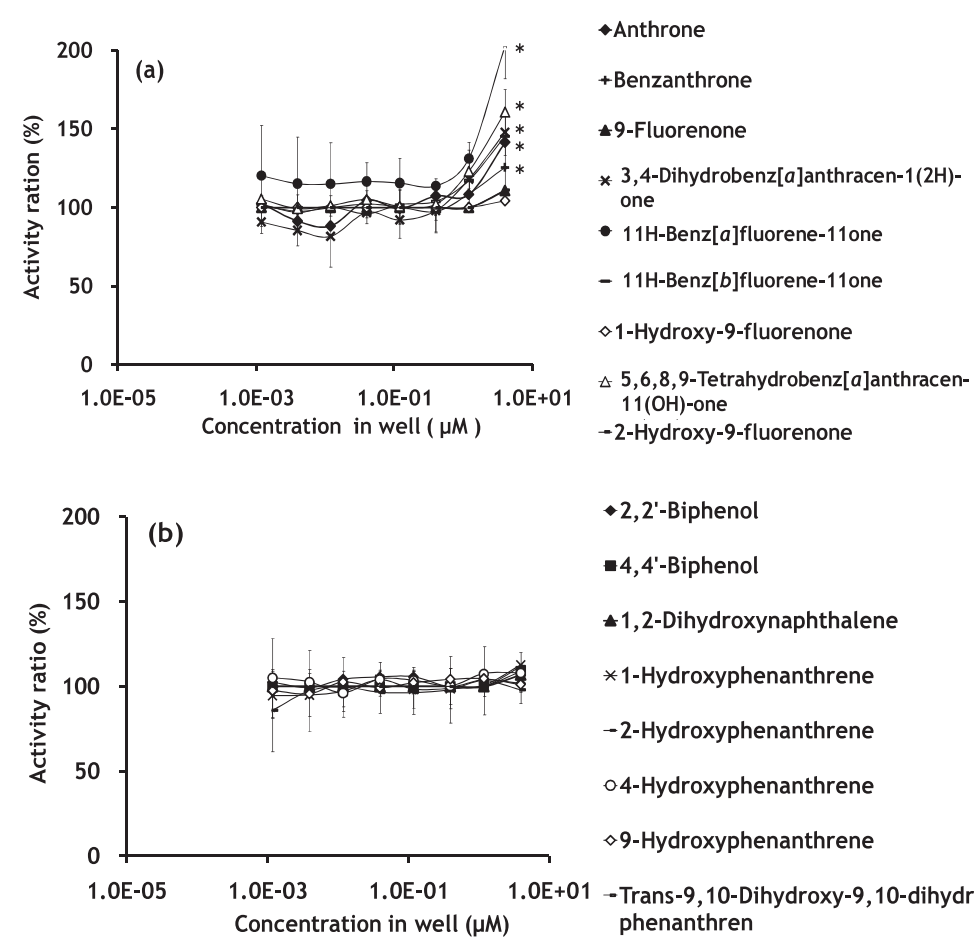

$\bullet 2,2$ '-Biphenol

-4,4'-Biphenol

$\star 1,2$-Dihydroxynaphthalene

*1-Hydroxyphenanthrene

-2-Hydroxyphenanthrene

०4-Hydroxyphenanthrene

$\diamond 9$-Hydroxyphenanthrene

1 - Trans-9,10-Dihydroxy-9,10-dihydrophenanthren

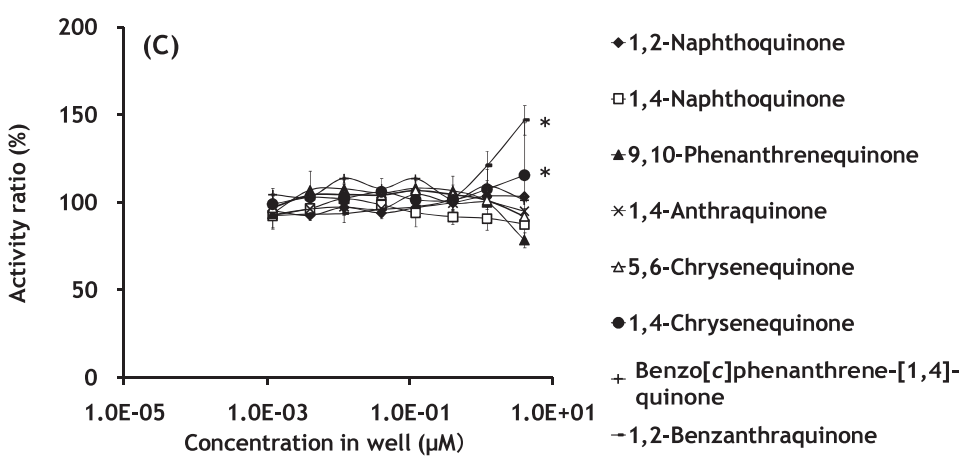

Fig. 4. TR $\beta$-potentiation Activity for the Tested PAH Derivatives

(a) PAH ketones, (b) PAH hydroxides, (c) PAH quinones. Potentiation activity of the PAH derivatives were expressed by the activity ratio. Activity ratio $=[$ Luciferase activity of the PAH derivative $+\mathrm{T} 3(2 \mathrm{nM}) /$ Luciferase activity of T3 $(2 \mathrm{nM})] \times 100$. Symbols and vertical bars respectively represent the mean and \pm S.D. $(n=5)$. Asterisk $(*)$ shows significant difference.

rectly to TR. However, some of these compounds showed potentiation effects via TR, suggesting a possibility that they interact with TR agonists (e.g., T3) or cofactors related to TR-mediated gene expressions. For revealing these mechanisms, an important finding was CYP1A production by the interaction of coexisting compounds, ${ }^{24)}$ although this has not yet been reported in the case of TR. The CYP1A is usually induced by the production of AhR and increasing binding activity of AhR-Arnt and Xenobiotics Responsive Elements $(\mathrm{XRE}){ }^{25)}$ Differently from this AhR relating reaction, phorbol-12-myristate-13-acetate (PMA) is not an AhR agonist (therefore, it does not cause XREbinding of AhR-Arnt), but it does enhance CYP1A1 expression in human hepatocellular carcinoma cells (HepG2)-derived cells. ${ }^{26,27)}$ This phenomenon also involves AhR-related modulation via another signaling pathway and is unrelated to the increase of AhR expression or the XRE-binding activity of AhR-Arnt. Such findings underscore the necessity of determining how TR potentiation is affected by PAHs and/or PAH derivatives.

Thyroid hormones are necessary for many physiological activities. They are especially important in early brain development requires thyroid hormones, ${ }^{28,29)}$ where they control neuronal and glial proliferation in definitive brain regions and regulate neuronal migration and differentiation. ${ }^{30)}$

Several polyhalogenated aromatic compounds 
bind to TTR, possibly resulting in the decrease of thyroid hormone level and negative effects on fetal brain development. Among those compounds, certain PCBs and their hydroxylated and methylsulfonate metabolites structurally resemble thyroid hormones and actually possess TTR-binding activities. ${ }^{31)}$ Especially, ortho-substituted PCB congeners are more neuroactive than the non-ortho-substituted congeners. ${ }^{32)}$ Metabolites of PCBs such as hydroxylated polychlorinated biphenyls (OH-PCBs) bind strongly to TTR. The in vivo effects of OH-PCBs on thyroidal mode of action through TTR might be explained by the following three hypotheses. First, TTR might work for selective retention of these compounds in plasma. Secondly, TTR might facilitate transport of the PCB metabolites over the placenta to the fetal compartment. Thirdly, TTR decreases maternal and fetal plasma T4 levels by competition with the natural ligand T4. ${ }^{10)}$ In fact, OH-PCBs have low affinities for human TR in vitro, ${ }^{33,34)}$ although they have a thyroid hormonelike affinity for serum TTR. Consequently, OHPCBs have actual effects through binding to TTR rather than binding to TR.

In this report, many PAH derivatives have binding activity to TTR. PAH quinones (1,4-NQ, 1,4$\mathrm{AQ}, 1,4-\mathrm{CQ}$ and $\mathrm{B}[c] \mathrm{P}-1,4-\mathrm{Q})$ have stronger activity than hydroxylated PAHs (Table 2). It is interesting that, from the viewpoint of structural features, the active compounds are para-quinone PAHs without 1,2-BAQ. Apparently, a similarity in structures exists between two active compounds: para-quinone PAHs and para-hydroxylated PCBs. These mechanisms are unknown still now, and further studies of structural activity relationship and investigations of more detail toxicity are needed. PAH derivatives have no halogen groups, which is a key to their persistence in vivo. Residual concentrations and persistency of PAH derivatives in vivo are also of concern when considering their risk in terms of endocrine disruption.

Acknowledgements We gratefully acknowledge the technical assistance of K. Mishima of the National Institute for Environmental Studies, Japan.

\section{REFERENCES}

1) Ames, B. N., McCann, J. and Yamasaki, E. (1975) Methods for detecting carcinogens and mutagens with the salmonella/ mammalian-microsome muta- genicity test. Mutat. Res., 31, 347-364.

2) Machala, M., Vondráček, J., Bláha, L., Ciganek, M. and Neča, J. (2001) Aryl hydrocarbon receptormediated activity of mutagenic polycyclic aromatic hydrocarbons determined using in vitro reporter gene assay. Mutat. Res., 497, 49-62.

3) Safe, S. H. (1995) Modulation of gene expression and endocrine response pathways by 2,3,7,8-tetrachlorodibenzo- $p$-dioxin and related compounds. Pharmacol. Ther, 67, 247-281.

4) Denison, M. S., Pandini, A., Nagy, S. R., Baldwin, E. P. and Bonati, L. (2002) Ligand binding and activation of the Ah receptor. Chem. Biol. Interact., 141, 3-24.

5) Allen, J. O., Dookeran, N. M., Taghizadeh, K., Lafleur, A. L., Smith, K. A. and Sarofim, A. F. (1997) Measurement of oxygenated polycyclic aromatic hydrocarbons associated with a sizesegregated urban aerosol. Environ. Sci. Technol., 31, 2064-2070.

6) Kishikawa, N., Nakao, M., Ohba, Y., Nakashima, K. and Kuroda, N. (2006) Concentration and trend of 9,10-phenanthrenequinone in airborne particulates collected in Nagasaki city, Japan. Chemosphere, 64, 834-838.

7) Penning, T. M., Burczynski, M. E., Hung, C. F., McCoull, K. D., Palackal, N. T. and Tsuruda, L. S. (1999) Dihydrodiol dehydrogenases, and polycyclic aromatic hydrocarbon activation: Generation of reactive and redox active $o$-quinones. Chem. Res. Toxicol., 12, 1-18.

8) Kizu, R., Ishii, K., Kobayashi, J., Hashimoto, T., Koh, E., Namiki, M. and Hayakawa, K. (2000) Antiandrogenic effect of crude extract of C-heavy oil. Mater. Sci. Eng., C, 12, 97-102.

9) Kappus, H. and Sies, H. (1981) Toxic drug effects associated with oxygen metabolism: Redox cycling and lipid peroxidation. Experientia, 37, 1233-1358.

10) Brucker-Davis, F. (1998) Effects of environmental synthetic chemicals on thyroid function. Thyroid, $\mathbf{8}$, 827-856.

11) Suzuki, G., Takigami, H., Watanabe, M., Takahashi, S., Nose, K., Asari, M. and Sakai, S. (2008) Identification of brominated and chlorinated phenols as potential thyroid-disrupting compounds in indoor dusts. Environ. Sci. Technol., 42, 1794-1800.

12) Brouwer, A., Morse, D. C., Lans, M. C., Schuur, A. G., Murk, A. J., Klasson-Wehler, E., Bergman, A. and Visser, T. J. (1998) Interactions of persistent environmental organohalogens with the thyroid hormone system: mechanisms and possible consequences for animal and human health. Toxicol. Ind. Health, 14, 59-84. 
13) Hanning, M. P. and Cass, G. R. (1998) Bioassaydirected chemical analysis of Los Angeles airborne particulate matter using a human cell mutagenicity assay. Environ. Sci. Technol., 32, 3502-3514.

14) Garrison, P. M., Tullis, K., Aarts, J. M., Brouwer, A., Giesy, J. P. and Denison, M. S. (1996) Speciesspecific recombinant cell lines as bioassay systems for detection of 2,3,7,8-tetrachlorodibenzo- $p$ dioxin-like chemicals. Fundam. Appl. Toxicol., 30, 194-203.

15) Hayakawa, K., Onoda, Y., Tachikawa, C., Yoshita, M., Toriba, A., Kameda, T. and Tang, N. (2008) Interaction of hydroxylated polycyclic aromatic hydrocarbons to estrogen receptor. Polycyclic Aromat. Compd., 28, 382-391

16) Behnisch, P. A., Hosoe, K. and Sakai, S. (2003) Brominated dioxin-like compounds: in vitro assessment in comparison to classical dioxin-like compounds and other polyaromatic compounds. Environ. Int., 29, 861-877.

17) Misaki, K., Matsui, S. and Matsuda, T. (2007) Metabolic enzyme induction by HepG2 cells exposed to oxygenated and nonoxygenated polycyclic aromatic hydrocarbons. Chem. Res. Toxicol., 20, 277-283.

18) Misaki, K., Kawami, H., Tanaka, T., Handa, Y., Nakamura, M., Matsui, S. and Matsuda, T. (2007) Aryl hydrocarbon receptor ligand activity of polycyclic aromatic ketones and polycyclic aromatic quinines. Environ. Toxicol. Chem., 26, 1370-1379.

19) Mahala, M., Ciganek, M., Blaha, L., Minksova, K. and Vondeack, J. (2001) Aryl hydrocarbon receptormediated and estrogenic activities of oxygenated polycyclic aromatic hydrocarbons and azaarenes originally identified in extracts of river sediments. Environ. Toxicol. Chem., 20, 2736-2743.

20) Kamiya, M., Toriba, A., Onoda, Y., Kizu, R. and Hayakawa, K. (2005) Evaluation of estrogenic activities of hydroxylated polycyclic aromatic hydrocarbons in cigarette smoke condensate. Food Chem. Toxicol., 43, 1017-1027.

21) Hayakawa, K., Onoda, Y., Tachikawa, C., Hosoi, S., Yoshita, M., Chung, S.W., Kizu, R., Toriba, A., Kameda, T. and Tang, N. (2007) Estrogenic/antiestrogenic activities of polycyclic aromatic hydrocarbons and their monohydroxylated derivatives by yeast two-hybrid assay. J. Health Sci., 53, 562-570.

22) Gillia, G., Pignataa, C., Schiliroà, T., Bonoa, R., La Rosab, A. and Traversia, D. (2007) The mutagenic hazards of environmental PM2.5 in Turin. Environ. Res., 103, 168-175.
23) Arthur, K. C., Sioutas, C., Miguel, A. H., Kumagai, Y., Schmitz, D. A., Singh, M., Fernandez, A. E. and Froines, J. R. (2005) Redox activity of airborne particulate matter at different sites in theLos Angeles Basin. Environ. Res., 99, 40-47.

24) Cherng, S. H., Lin, P., Yang, J. L., Hsu, S. L. and Lee, H. (2001) Benzo[ $[g, h, i]$ perylene synergistically transactivates benzo $[a]$ pyrene-induced CYP1A1 gene expression by aryl hydrocarbon receptor pathway. Toxicol. Appl. Pharmcol., 170, 6368.

25) Fertuck, K. C., Kumar, S., Sikka, H. C., Matthews, J. B. and Zacharewski, T. R. (2001) Interaction of PAH-related compounds with the $\alpha$ and $\beta$ isoforms of the estrogen receptor. Toxicol. Lett., 121, 167177.

26) Long, W. P., Pray-Grant, M., Tsai, J. C. and Perdew, G. H. (1998) Protein kinase C activity is required for aryl hydrocarbon receptor pathway-mediated signal transduction. Mol. Pharmacol., 53, 691-700.

27) Chen, Y.-H. and Turkey, R. H. (1996) Protein kinase $\mathrm{C}$ modulates regulation of the CYP1A1 gene by the aryl hydrocarbon receptor. J. Biol. Chem., 271, 26261-26266.

28) Howdeshell, K. L. (2002) A model of the development of the brain as a construct of the thyroid system. Environ. Health Perspect., 110, 337-348.

29) Colborn, T. (2004) Neurodevelopment and endocrine disruption. Environ. Health Perspect., 112, 944-949.

30) Chan, S. and Kilby, M. D. (2000) Thyroid hormone and central nervous system development. $J$. Endocrinol., 165, 1-8.

31) Porterfield, S. P. (2000) Thyroidal dysfunction and environmental chemicals-potential impact on brain development. Environ. Health Perspect., 108(Suppl.), 433-438.

32) McKinney, J. D. and Waller, C. L. (1994) Polychlorinated biphenyls as hormonally active structural analogues. Environ. Health. Perspect., 102, 290297.

33) Maier, W. E., Kodavanti, P. R., Harry, G. J. and Tilson, H. A. (1994) Sensitivity of adenosine triphosphatases in different brain regions to polychlorinated biphenyl congeners. J. Appl. Toxicol., 14, 225-229.

34) Cheek, A. O., Kow, K., Chen, J. and McLachlan, J. A. (1999) Potential Mechanisms of Thyroid Disruption in Humans: Interaction of organochlorine Compounds with Thyroid Receptor, Transthyretin, and Thyroid-binding Globulin. Environ. Health Perspect., 107, 273-278. 